\title{
Study of Supracondylar Spur of the Humerus in Jharkhand Population
}

\author{
Alka Rashmi Nag ${ }^{1}$, Shilpa Singh ${ }^{2}$, Renu Prasad ${ }^{3}$ \\ ${ }^{1,2}$ Junior Residents, ${ }^{3}$ Professor and HOD, Department of Anatomy, Rajendra Institute of \\ Medical Sciences, Ranchi
}

\begin{abstract}
:
Introduction: Supracondylar spur is a bony projection about 2-20 $\mathrm{mm}$ in length, occasionally projects from the anteromedial surface of the shaft of humerus about $5 \mathrm{~cm}$ proximal to the medial epicondyle. It represents an embryonic vestigial remnant in climbing animals and felines. It may be joined to the medial epicondyle by a fibrous band called ligament of struthers, which may ossify. It is usually asymptomatic but can present with the symptoms like median nerve and brachial artery compression when associated with struthers ligament.

Materials and Methods: 127 dried humeri were studied from the department of anatomy, RIMS, Ranchi. Bones were examined for supracondylar spur, its dimensions were recorded with vernier caliper and photographs taken.

Result: Out of 127 dried humeri only one humerus with supracondylar spur of length $2.4 \mathrm{~cm}$ was found on the anteromedial surface of left humerus at a distance of $5.6 \mathrm{~cm}$ from the tip of medial epicondyle. The incidence calculated in our study was $0.78 \%$.

Conclusion: Its incidence reported in past varies from $0.1 \%$ to $2.7 \%$ in different races. Our study revealed its low incidence in Jharkhand population.
\end{abstract}

\section{Introduction}

Supracondylar Spur was first described by Sir John Struthers a Scottish anatomist in $1849^{[1]}$. Synonyms include: supracondylar spur, supracondyloid process, supratrochlear process, epicondylar process, epicondylic process, and avian spur ${ }^{[1]}$.Supracondylar spur is a hook shaped bony projection, about 2-20 mm in length, occasionally projects from the anteromedial surface of the shaft of humerus about $5 \mathrm{~cm}$ proximal to the medial epicondyle ${ }^{[2]}$. The spur may often be joined to the medial epicondyle by a fibrous band called ligament of Struthers, that may ossify and give attachment to a portion of the abnormally low fibers (the third head) of the coracobrachialis muscle and may also give origin to the pronator teres muscle ${ }^{[3]}$ The foramen so formed usually encloses the median nerve and brachial artery, but sometimes only the nerve or perhaps nerve plus ulnar artery in a high division of brachial artery ${ }^{[2]}$ Compression and claudication of brachial Artery has been reported by Hafid et al ${ }^{(4)}$. However,Quain ${ }^{(5)}$

described a rare case of ulnar artery compression. The incidence varies from $0.1 \%$ to $2.7 \%$. Terry reported finding of supracondylar spur in 6 of 515(1.16\%) Whites but only 1 in $1000(0.1 \%)$ Negroes. It is a normal anatomical structure in climbing animals. It represents the embryological vestigial remanant of climbing animals and seen in many repti;les, most marsupials, cats, lemurs and American monkeys . The present study aims to find out the incidence and morphometry of supracondylar spur in Jharkhand population.

\section{Materials And Methods}

The study was conducted on 127 dried humeri which were collected from Department of Anatomy, Rajendra Institute of Medical Sciences, Ranchi, Jharkhand, India. The bones were examined for any osseous projection from distal part under daylight. On finding a supracondylar process, the dimensions of projection were recorded with vernier caliper and photographs were taken.

\section{Observation}

Out of 127 dried humeri only one humerus had the supracondylar spur. The incidence calculated in our study was $0.78 \%$. The humerus was of left side with supracondylar spur on the anteromedial surface.

- Length of the spur $-2.4 \mathrm{~cm}$

- Length at the base $-1.6 \mathrm{~cm}$

- $\quad$ Breath at the base $-0.6 \mathrm{~cm}$

- Distance from anterior border $-1 \mathrm{~cm}$

- Distance from medial border $-0.9 \mathrm{~cm}$

- Distance from nutrient foramen $-4.1 \mathrm{~cm}$ 
- Distance from the tip of medial epicondyle $-5.6 \mathrm{~cm}$

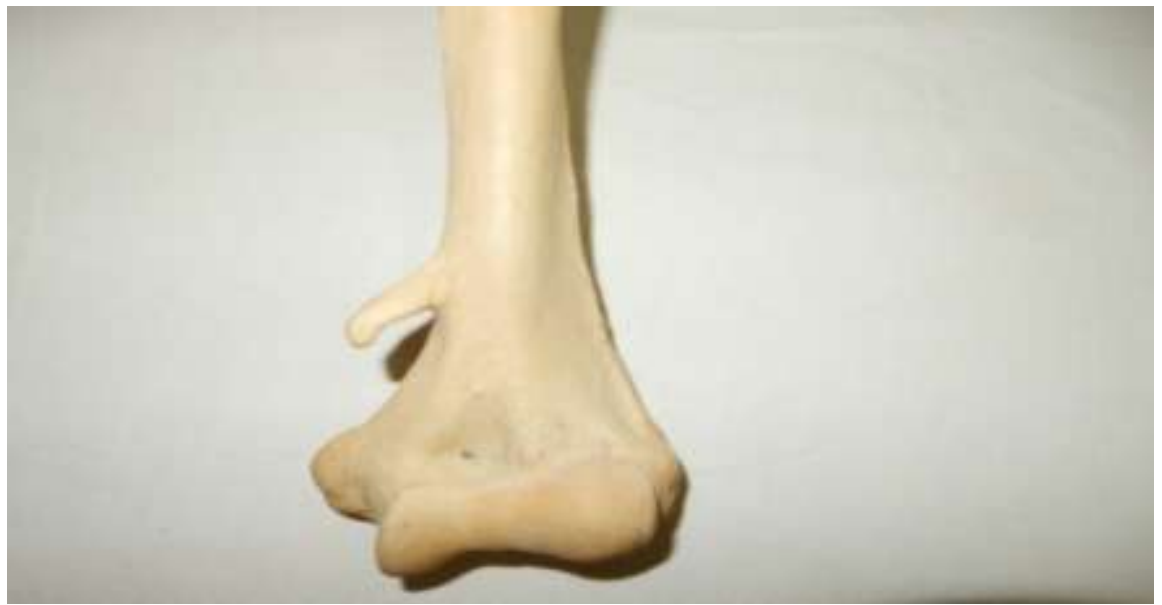

Fig 1: Showing distal part of left humerus with supracondyla

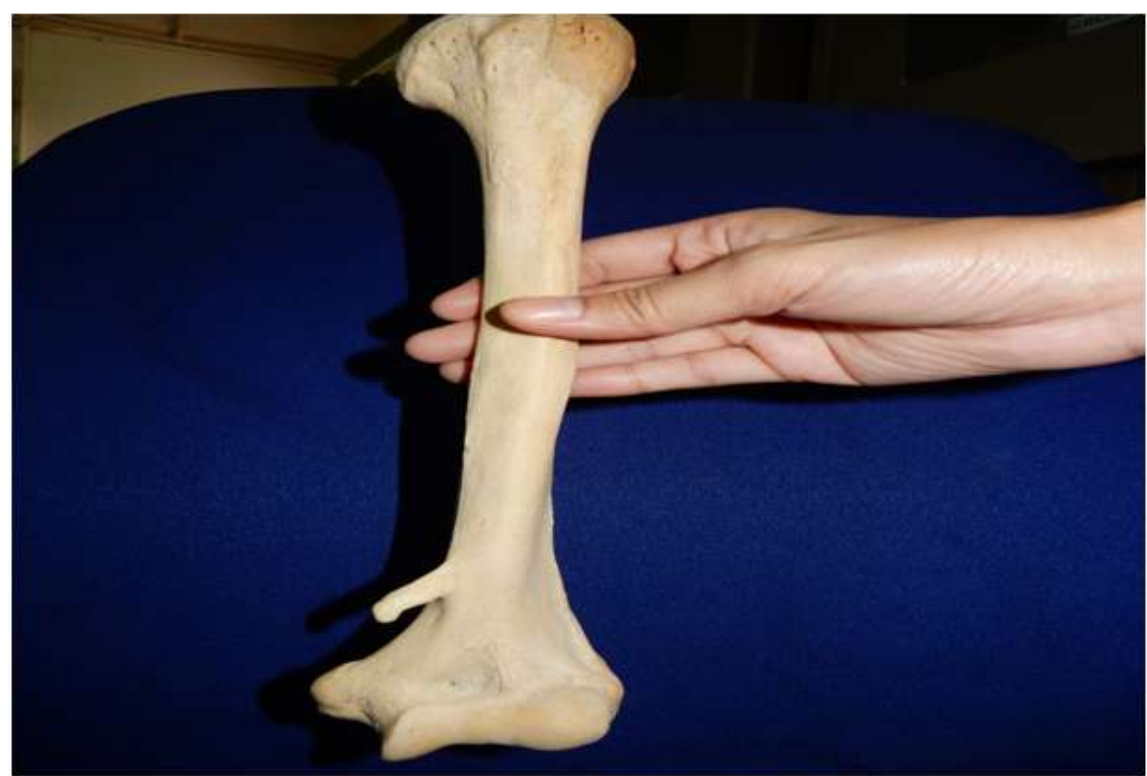

Fig. 2 : Showing left humerus with supracondylar spur.

\section{Discussion}

Some anatomists believe that the spur is a vestigial structure found in climbing mammals and felines that once served as the insertion of the muscle latissimocondyloideus. This might explain why it may occasionally be found as an anatomic variant in humans ${ }^{[8]}$

The supracondylar process is a rudimentary homologue of the supracondylar foramen or entepicondylar foramen found in lower animals. It has a protective role in members of the cat family. It forms the roof of a foramen that transmits the neurovascular bundle ${ }^{[2]}$

Previous studies have reported a relatively higher incidence of the spur in European Caucasians as compared to colored races. ${ }^{[5]}$ The reported incidence of SCS varies from $0.1 \%$ to $2.7 \%$ in different races. ${ }^{[8]}$ In our study the incidence calculated was $0.78 \%$ which comes within this range and is very close to the result found by Ravi vandana 2014. Its presence may aid in assessing racial affinities . ${ }^{[2]}$ The incidence of supracondylar spur as given by different authors varies(Table No. 1).There is a high incidence of unilateral supracondylar spur of the humerus in Cornelia de Large syndrome, an autosomal recessive trait, occurring in approximately one in every 10,000 live birth.${ }^{(9)}$ From embryological point of view the struther's ligament lies between the tendon of the latissimus dorsi and the coracobrachialis and corresponds to the lower part of the tendon of the vestigial latissimocondyloideus a muscle found in climbing mammals which extends from the tendon of insertion of the latissimus dorsi muscle to the medial epicondyle ${ }^{(10)}$ 
Table No. 1: Previous studies on supracondylar spur revealed the following data:

\begin{tabular}{|c|l|c|c|c|c|c|}
\hline S.No & Name of Author & Year & N & SCS & Incidence & Avg. Length \\
\hline 1 & Lattupalli Hema & 2015 & 152 & 1 & $0.65 \%$ & $20 \mathrm{~mm}$ \\
\hline 2 & Shivaleelac & 2014 & 240 & 1 & $0.41 \%$ & $10 \mathrm{~mm}$ \\
\hline 3 & Ravi Vandana & 2014 & 133 & 1 & $0.75 \%$ & $8 \mathrm{~mm}$ \\
\hline 4 & Shiny Vinillash & 2014 & 70 & 2 & $2.80 \%$ & $6.5 \mathrm{~mm}$ \\
\hline 5 & Prabahita Baruah & 2012 & 80 & 1 & $1.25 \%$ & $11 \mathrm{~mm}$ \\
\hline 6 & Ganesan Murgaperumal & 2012 & 30 & 1 & $3.30 \%$ & $10 \mathrm{~mm}$ \\
\hline 7 & Gupta R K & 2008 & 380 & 1 & $0.26 \%$ & $3 \mathrm{~mm}$ \\
\hline 8 & Natsis & 2008 & 750 & 10 & $1.30 \%$ & $9.5 \mathrm{~mm}$ \\
\hline 9 & Oleyemi K A & 2007 & 40 & 1 & $2.50 \%$ & $16 \mathrm{~mm}$ \\
\hline
\end{tabular}

N-Number of bones studied

SCS-Number of bones with Supracondyla Spur (SCS) found

Avg. Length - Average length of SCS

\section{Clinical Implications}

- Supracondylar process of humerus is usually an incidental finding in radiographs can also be diagnosed by palpation.

- Pressure from the ligament on the artery or nerve may very rarely cause an irritative spasm of the vessel or a median nerve palsy. Such palsy can mimic "carpal tunnel syndrome",.[3]

- Entrapment of brachial artery and median nerve by this ligament at the level of supracondylar spur is known as supracondylar process syndrome which can be treated by surgical removal of the process and ligament.(11)

- The compression symptoms include severe paresthesia and hyperesthesia of hand and fingers, ischemic pain of forearm, embolization of distal arm arteries and disappearance of radial or ulnar pulse on full extension and supination of the forearm. $(10,12)$

- In case of high division of brachial artery, the ulnar artery may be compressed while passing beneath the ligament along with the median nerve.

- It is necessary that the spur has to be resected with its periosteum and the binding fibers of pronator teres that arise from it to prevent regeneration of the spur and recurrence of symptoms.[12]

- $\quad$ Rare cases of fractures of the process have also been reported.

\section{Conclusion}

- The knowledge of supracondylar spur is important for clinicians, orthopaedic surgeons, radiologists and anatomists.

- Symptoms due to supracondylar spur of humerus, although rare are common enough to make it the subject of routine examination with pain and disturbance of sensibility of hand.

- The awareness of supracondylar spur is important for the orthopaedic surgeons, as it may affect the preoperative planning in case of distal humerus fracture, the possibility of a supracondylar spur must be suspected in patients presenting with symptoms of median or ulnar nerve entrapment, as radiologists need to be familiar with the variants in order to avoid misdiagnosis during interpretation of plain radiographs and computed tomography scans of the distal third of the humerus.

- Our study revealed the low incidence of supracondylar spur in Jharkhand population.

\section{References}

[1]. Struthers J. On a peculiarity of the humerus and humeral artery. Mon J Med Sci (new series 28) 1848;8:264-7.

[2]. Standring S (2008) Gray’s Anatomy. 40th edit. Elsevier Churchill Livingstone, Edinburgh, p 798.

[3]. R.J. Last Anatomy, regional and applied (7th ed)ELBS/Churchill Livingstone, Edinburgh, U.K (1984), pp. 73-74

[4]. Hafid Halha, Bernard Enon, Jean-Michel Chevalier, Philippe L'Hoste, Jean Pillet. Brachial artery entrapment : compression by the supracondylar process.Journal Annals of vascular surgery.1987:1(4):479-82.

[5]. Quain R.Anatomy of the arteries of the human body. London: Taylor \& Walker: 1844.

[6]. I. alNaib Humeral supracondylar spur and Struthers' ligament. A rare cause of neurovascular entrapment in the upper limb Int Orthop, 18 (1994), pp. 393-394

[7]. Aydinlioglu A, Gumrukcuoglu FN, Koyun N. The prevalence of the supracondyloid process in the living: A radiographic study. West Indian Med J. 2010; 59: 545-548.

[8]. Gupta RK, Mehta CD (2008) A study of the incidence of supracondylar process of the humerus. J Anat Soc India, 57: 111-115

[9]. Peters FLM.Radiologic manifestations of Cornelia de Lange syndrome.Pediatr Radiol.1975;3:41-46.

[10]. Kessel L, Ring M.The supracondylar spur of the humerus.J Bone Joint Surg.1976;48:765-66.

[11]. Pecina M, Boric I, Anticevic D.Intraoperatively proven anomalous Struthers. Ligament diagnosed by MRI Skeletal Radiol.2002:31(9):532-35.

[12]. Barnard LB, McCoy SM. The supracondyloid process of the humerus. J Bone Joint Surg Am. 1946; 28: 845-850 